УДК 542.06.542.61.542.46.808.542.97.542.93

\title{
МАСС-СПЕКТРОМЕТРИЯ И КВАНТОВОХИМИЧЕСКОЕ ИССЛЕДОВАНИЕ ПРОЦЕССОВ САМОАССОЦИАЦИИ МОЛЕКУЛ ГЛИЦИРРИЗИНОВОЙ
}

\section{кислоты}

(ㄱ С.Н. Борисенко ${ }^{1}$, А.В. Лекарь ${ }^{2}$, А.А. Милов ${ }^{3}$, Е.В. Ветрова ${ }^{1}$, Н.И. Борисенко ${ }^{*}$

\author{
${ }^{1}$ НИИ физической и органической химии Южного федерального \\ университета, пр. Стачки, 194/2, Ростов-на-Дону, 344090 (Россия) \\ ${ }^{2} Э$ эолого-аналитический центр Южного Федерального университета, \\ ул. Зорге, 7, Ростов-на-Дону, 344090 (Россия), e-mail: boni@ipoc.rsu.ru \\ ${ }^{3}$ Южный научный центр РАН, пр. Чехова, 41, Ростов -на-Дону, 344006 \\ (Россия)
}

\begin{abstract}
Метод масс-спектрометрии с ионизацией электрораспылением использован для изучения процессов формирования автоассоциатов глицирризиновой кислоты (ГК). Данные масс-спектрометрии доказывают наличие димеров и тримеров ГК для образцов 0,2\%-ного раствора моноаммониевой соли глицирризиновой кислоты при рН 5,5 и 2. Полученные данные согласуются с квантово-химическими расчетами самоассоциатов глицирризиновой кислоты. Квантовохимическими расчетами показано, что для глицирризиновой кислоты возможно образование кластеров общего вида Хn со значением $\mathrm{n}$ от 1 до $\mathrm{n}=6$. При этом как по данным масс-спектрометрии, так и по результатам квантово-химических расчетов наибольшей стабильностью обладают кластеры, построенные по принципу «голова-хвост». В ассоциате ГК, состоящем из двух молекул, присутствует полость, достаточная для включения соразмерных молекул-гостей.

Ключевые слова: самоассоциация, глицирризиновая кислота, масс-спектрометрия, ионизация электрораспылением, квантовохимические расчеты, комплексообразование, супрамолекулярные комплексы.
\end{abstract}

Работа выполнена при финансовой поддержке гранта РФФИ 11-03-12141-офи-м-2011, грантов Президента РФ по поддержке ведущих научных школ НШ-927.2012.3, МК-4425.2011 и гос. задания вузам на 2012 год (проект 3.5193.2011).

\section{Введение}

Четкое понимание механизмов терапевтического действия лекарственных препаратов на молекулярном уровне является одной из важнейших задач биохимии и медицинской химии, поскольку понимание процессов связывания и диссоциации лиганд - рецепторных комплексов - позволяет выявить причину дей-

Борисенко Сергей Николаевич - кандидат химических наук, старший научный сотрудник, тел.: (863) 224-12-74, e-mail: sborisen@ipoc.rsu.ru Лекарь Анна Владимировна - старший лаборант, тел. (863) 224-12-74, e-mail: lekarann@mail.ru Милов Алексей Александрович - кандидат химических наук, научный сотрудник, тел.: 908 510-88-00, e-mail: c-si-ge@mail.ru

Ветрова Елена Владимировна - кандидат биологических наук, старший научный сотрудник, тел.: (863) 224-12-74, e-mail: firefuntik@ mail.ru Борисенко Николай Иванович - директор, кандидат химических наук, доцент, тел.: (863)-224-12-74, e-mail: boni@ipoc.rsu.ru ствия лекарства, разработать методы для контроля действия лекарства и минимизировать возможные побочные эффекты для организма. До настоящего времени такие процессы изучены недостаточно полно: отсутствуют четкие представления о механизмах связывания лекарства с рецептором, нет данных о дальнейшей трансформации комплекса на активном центре рецептора, ведущей к его диссоциации. Одним из классов биологически активных веществ, широко используемых в качестве адъювантных средств (adjuvants), являются сапонины, чья селективная способность к образованию ассоциатов с молекулами

\footnotetext{
* Автор, с которым следует вести переписку.
} 
других веществ известна давно [1]. Это свойство сапонинов применяется в настоящее время при направленном поиске новых лекарственных субстанций с заданными характеристиками на основе комплексов типа «хозяин-гость» [2]. Привлекательность такого подхода состоит в том, что в качестве базового фрагмента можно использовать композиции известных, клинически апробированных препаратов. Кроме того, применение уже испытанных препаратов позволяет значительно снизить затраты на доклинические исследования и клиническую апробацию новых композиций.

Так, в настоящее время активно создаются лекарственные субстанции на основе известных базовых физиологически активных компонентов (фармаконов) и глицирризиновой кислоты (ГК) $[3,4]$. При этом было обнаружено значительное количество примеров усиления действия ряда фармаконов в комплексах с ГК [5, 6], что позволяет уменьшить эффективные дозы лекарственных препаратов в 100-200 раз.

В процессах получения таких комплексов молекулы глицирризиновой кислоты выступают в роли полидентантных лигандов, образующих с базовыми фармаконами комплексы различной стехиометрии, которые и используются как низкодозные лекарственные субстанции. Изучение механизмов и процессов образования супрамолекулярных комплексов по типу «гость-хозяин», где сапонин, в качестве молекулы«хозяина», может образовывать в гидрофильной среде эндолипофильную полость для молекулы гостя [7, 8], особенно важно для установления фундаментальных связей «структура-свойства».

При всей многочисленности примеров использования такого подхода [3-6] детали механизма процесса формирования низкодозных лекарственных комплексов глицирризиновой кислоты $\mathbf{1} \mathrm{c}$ фармаконами в различных соотношениях $(1: 1,1: 2$ и $1: 4)$ до сих пор изучены недостаточно. Практически не известны данные по геометрии и свойствам самоассоциатов глицирризиновой кислоты, которые и определяют в значительной степени возможность образования полости внутри самоассоциатов глицирризиновой кислоты, так необходимой для размещения молекулы базового фармакона.

В этой связи целью данной работы стало доказательство формирования автоассоциатов ГК методами масс-спектрометрии с ионизацией электрораспылением и проведение квантово-химических расчётов для предсказания геометрии и свойств автоассоциатов глицирризиновой кислоты 1.

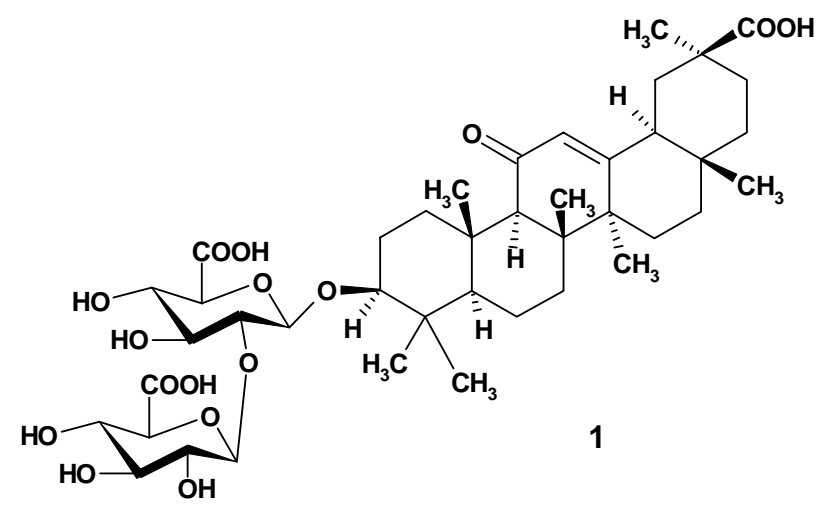

\section{Экспериментальная часть}

Съемки масс-спектров проведены с использованием масс-спектрометра «Bruker Daltonics micrOTOFQ» с вводом пробы напрямую, ионизация электрораспылением, детектирование отрицательных и положительных ионов в интервале от 50 до 3000 Да с точностью не менее $1 \times 10^{-2}$ Да. Напряжение на капилляре распылителя - $\pm 4200 \mathrm{~B}$, параметры газа-осушителя (азот «о.с.ч.», 5 л/мин, $200^{\circ} \mathrm{C}$ ) и энергия ионов на квадруполе (5,0 эВ) оптимизированы для детектирования пиков псевдомолекулярных и ассоциатных ионов.

Для прямого ввода взяты растворы в ацетонитриле (фирма Merck, квалификация HPLC/MS) в концентрации до 0,2 мг/мл (10-7 $\div 10-6$ М). Результаты масс-спектрометрии приведены в таблице 1.

Масс-спектры автоассоциатов глицирризиновой кислоты 1 получены для 0,2\%-ного раствора моноаммониевой соли глицирризиновой кислоты при $\mathrm{pH}=5,5$ и 2 (добавка муравьиной кислоты).

Квантово-химические расчеты проводились при помощи пакета программ Gaussian-03 [9] полуэмпирическим методом РМ3. Выбор этого приближения обусловлен размерами изучаемых ассоциатов, накладывающих ограничения на использование методов $a b$ initio и теории функционала плотности [10]. Все 
обсуждаемые далее структуры соответствуют минимумам на соответствующих поверхностях потенциальной энергии. Графические изображения молекулярных структур, представленные на рисунках, были получены с использованием программы Chemcraft [11], где в качестве исходных данных использовались результаты расчетов.

\section{Обсуждение результатов}

Для оценки возможностей масс-спектрометрии с ионизацией электрораспылением при доказательстве существования автоассоциатов ГК заключений сняты масс-спектры 0,2\%-ного раствора моноаммониевой соли глицирризиновой кислоты при $\mathrm{pH}=5,5$ и 2 (добавка муравьиной кислоты)моноаммонийной

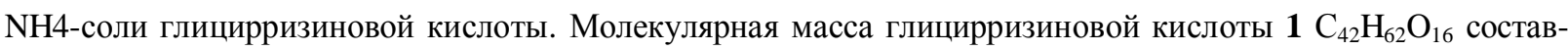
ляет 822,370 Да. Типичный масс-спектр моноаммонийной $\mathrm{NH}_{4}$-соли глицирризиновой кислоты приведен на рисунке 1.

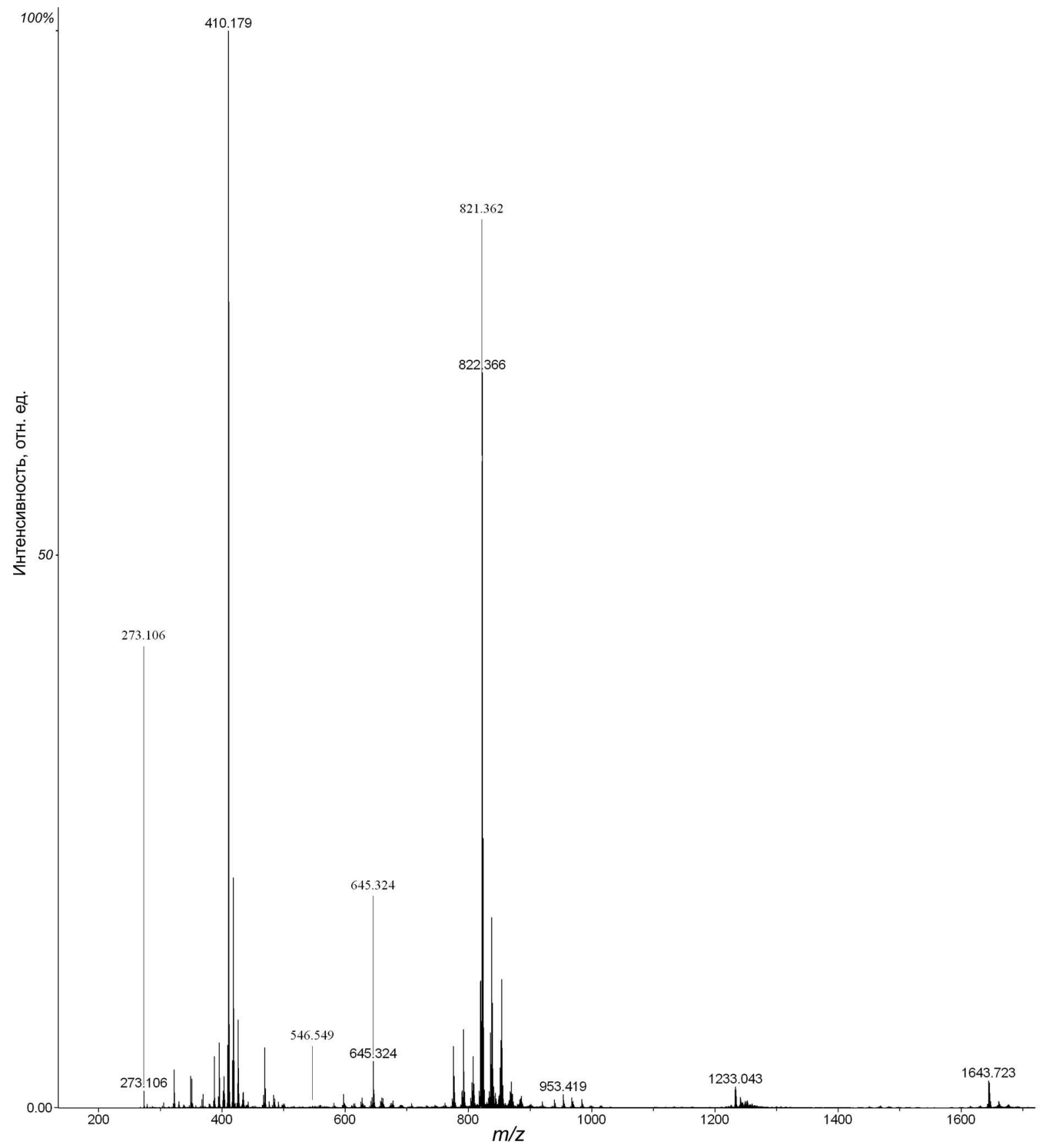

Рис. 1. Масс-спектр моноаммонийной $\mathrm{NH}_{4}$-соли глицирризиновой кислоты при $\mathrm{pH}=2$ 
Масс-спектры моноаммонийной $\mathrm{NH}_{4}$-соли глицирризиновой кислоты при $\mathrm{pH}=2$ (рис. 1) регистрируют, при выбранных экспериментальных условиях, как наличие однозарядных пиков, отвечающих как молекулярному иону глицирризиновой кислоты, так и однозарядных пиков, соответствующих самоассоциатам кислоты.

Так, например, пик, регистрируемый с $\mathrm{m} / z$ 821,36 (67\% интенсивности), отвечает мономерному аниону [М-Н]” кислоты 1.

Димерному (содержащему две молекулы глицерризиновой кислоты) однозарядному моноаниону [2М-Н]' однозначно отвечает пик (3\% интенсивности) с массой 1643,723 Да.

На этом же спектре регистрируется в отрицательных ионах, наряду с пиками мономеров и димеров ГК, двухзарядный пик с $m / z$ 1232,541 (12\% интенсивности), который отвечает тримерному автоассоциату кислоты 1. Такой тример может иметь строение сэндвича $[(\mathrm{M}-\mathrm{H})+\mathrm{M}+(\mathrm{M}-\mathrm{H})]^{-2}$ или $[\mathrm{M}+(\mathrm{M}-2 \mathrm{H})+\mathrm{M}]^{-2}$ (табл.).

Так как глицирризиновая кислота 1 является трехосновной кислотой, ее масс-спектр содержит, соответственно, пики мономерных псевдомолекулярного трианиона $[\mathrm{M}-3 \mathrm{H}]^{-3}$ с $\mathrm{m} / \mathrm{z}, 273,106$ и изотопного трианиона $[\mathrm{M}-3 \mathrm{H}+1]^{-3} \mathrm{c} \mathrm{m} / \mathrm{z}, 273,443$ (рис. 2).

Интенсивность пика $[\mathrm{M}-3 \mathrm{H}]^{-3}$ в 54 раза меньше интенсивности пика $[\mathrm{M}-2 \mathrm{H}]^{-2}$ и в 36 раз меньше интенсивности пика $[\mathrm{M}-\mathrm{H}]^{-}$, следовательно, в условиях ионизации электрораспылением при $\mathrm{pH}=2$ трехосновная кислота 1 диссоциирует, в основном, по первой и второй ступеням.

В масс-спектре наблюдается пик с $m / z$ 547,218, который отвечает димерному трианиону [(М-H)+(М$2 \mathrm{H})]^{-3}$. Тримерному трехзарядному аниону $\left.[3 \mathrm{M}-3 \mathrm{H})\right]^{-3}$ в таком случае в масс-спектре должен соответствовать пик с $m / z$ 821,36. Такой пик, однако, достоверно в полученных масс-спектрах не фиксируется. Последнее может объясняться тем, что его интенсивность $\leq 10^{2}$. Убывание интенсивности пиков в ряду трехзарядных анионов $[\mathrm{M}-3 \mathrm{H}]^{-3}(2,3 \times 104),[2 \mathrm{M}-3 \mathrm{H}]^{-3}(2,9 \times 103)$ и ожидаемого $[3 \mathrm{M}-3 \mathrm{H}]^{-3}(\leq 102)$ позволяет прогнозировать практическое отсутствие трехзарядных анионов со степенью ассоциации более 3 , при выбранных условиях ионизации. Наблюдаемые зависимости напрямую связаны с возрастанием роли кулоновских взаимодействий в процессах ионизации тримерных и выше ассоциатов.

Кулоновским отталкиванием можно объяснить также отсутствие димерных тетраанионов [(М$2 \mathrm{H})+(\mathrm{M}-2 \mathrm{H})]^{-4}$ и $[(\mathrm{M}-\mathrm{H})+(\mathrm{M}-3 \mathrm{H})]^{-4}$, что подтверждено отсутствием пиков с $m / z 410,179$ для иона $[2 \mathrm{M}-4 \mathrm{H}]^{-4}$.

Характерно, что с увеличением $\mathrm{pH}$ от 2 до 5,5 доля трехзарядного аниона $[\mathrm{M}-3 \mathrm{H}]^{-3}$ с $\mathrm{m} / \mathrm{z} 273,106$ увеличивается на 65\%, тогда как доли ди- и моноанионов кислоты 1 изменяются менее существенно.

Таким образом, данные масс-спектрометрии с ионизацией электрораспылением подтверждают, что глицирризиновая кислота 1 образует димерные автоассоциаты за счет свободных карбоксильных групп в углеводной цепи и при атоме C-28 агликона. Причем устойчивость этих комплексов достаточна для преодоления кулоновского отталкивания в трианионе. Наибольшее зарегистрированное значение коэффициента ассоциации составляет 3 (автоассоциат [3М-2H] ${ }^{-2}$ с $\mathrm{m} / \mathrm{z}, 1232,541$; см. табл.).

Для объяснения полученных экспериментальных результатов выполнены квантово-химические расчеты кластеров ГК общего вида $\mathrm{Xn}(\mathrm{n}=1-6)$. Показано, что бимолекулярная система ГК $(\mathrm{n}=2)$ образует устойчивые структуры $\mathbf{2 - 4}$, которые стабилизируются системой водородных мостиковых $\mathrm{O}-\mathrm{H}-\mathrm{O}$ связей. Характеристики данных структур приведены рисунке 3, где, в частности, показаны наименьшие длины связи между молекулами ГК. Комплекс 2 относится к типу «голова-голова», а комплексы 3-4 имеют структуру «голова-хвост». Расчеты показывают, что наибольшей устойчивостью обладают ассоциаты 3-4, энергии комплексообразования которых составляют 15-16 ккал/моль, что согласуется с моделью стабилизации димерных ассоциатов ГК по типу «голова к хвосту». Необходимо отметить, что наиболее энергетически устойчивый бимолекулярный ассоциат 4 имеет внутреннюю полость, достаточную для включения соразмерных молекул-гостей.

Косвенным подтверждением расчетных данных об образовании димерных ассоциатов кислоты 1 по типу «голова-хвост» может служить отсутствие в масс-спектрах (рис. 1) пика, отвечающего тримерному ассоциату [M+(M-H)+M] ${ }^{-} \mathrm{c} m / 2,2466,10$.

Таким образом, данные масс-спектрометрии и результаты квантово-химических расчетов подтверждают формирование автоассоциатов глицирризиновой кислоты, при этом наибольшей стабильностью обладают димерные кластеры ГК, построенные по принципу «голова-хвост». Димерные кластеры ГК, по данным расчета, имеют внутреннюю полость, достаточную для включения соразмерных молекул-гостей $[7,8]$. 
Наличие и строение автоассоциатов глицирризиновой кислоты 1

\begin{tabular}{c|c|c|c|c}
\hline Соотношение $m / z$ & Заряд z & Строение иона & $\begin{array}{c}\text { Коэффициент } \\
\text { ассоциации }\end{array}$ & $\begin{array}{c}\text { Относительная } \\
\text { доля иона }\end{array}$ \\
\hline 273,106 и 273,443 & -3 & {$[\mathrm{M}-3 \mathrm{H}]^{-3}$} & 1 & 8 \\
410,179 и 410,678 & -2 & {$[\mathrm{M}-2 \mathrm{H}]^{-2}$} & 1 & 429 \\
547,218 и 547,560 & -3 & {$[(\mathrm{M}-\mathrm{H}) \ldots(\mathrm{M}-2 \mathrm{H})]^{-3}$ или $[\mathrm{M} \ldots(\mathrm{M}-3 \mathrm{H})]^{-3}$} & 2 & 1 \\
821,362 & -1 & {$[\mathrm{M}-\mathrm{H}]^{-}$} & 1 & 286 \\
1232,541 & -2 & {$[(\mathrm{M}-\mathrm{H}) \ldots \mathrm{M} \ldots(\mathrm{M}-\mathrm{H})]^{-2}$} & 3 & 52 \\
1643,723 & -1 & или $[\mathrm{M} \ldots(\mathrm{M}-2 \mathrm{H}) \ldots \mathrm{M}]^{-2}$ & 2 & 13 \\
\hline
\end{tabular}

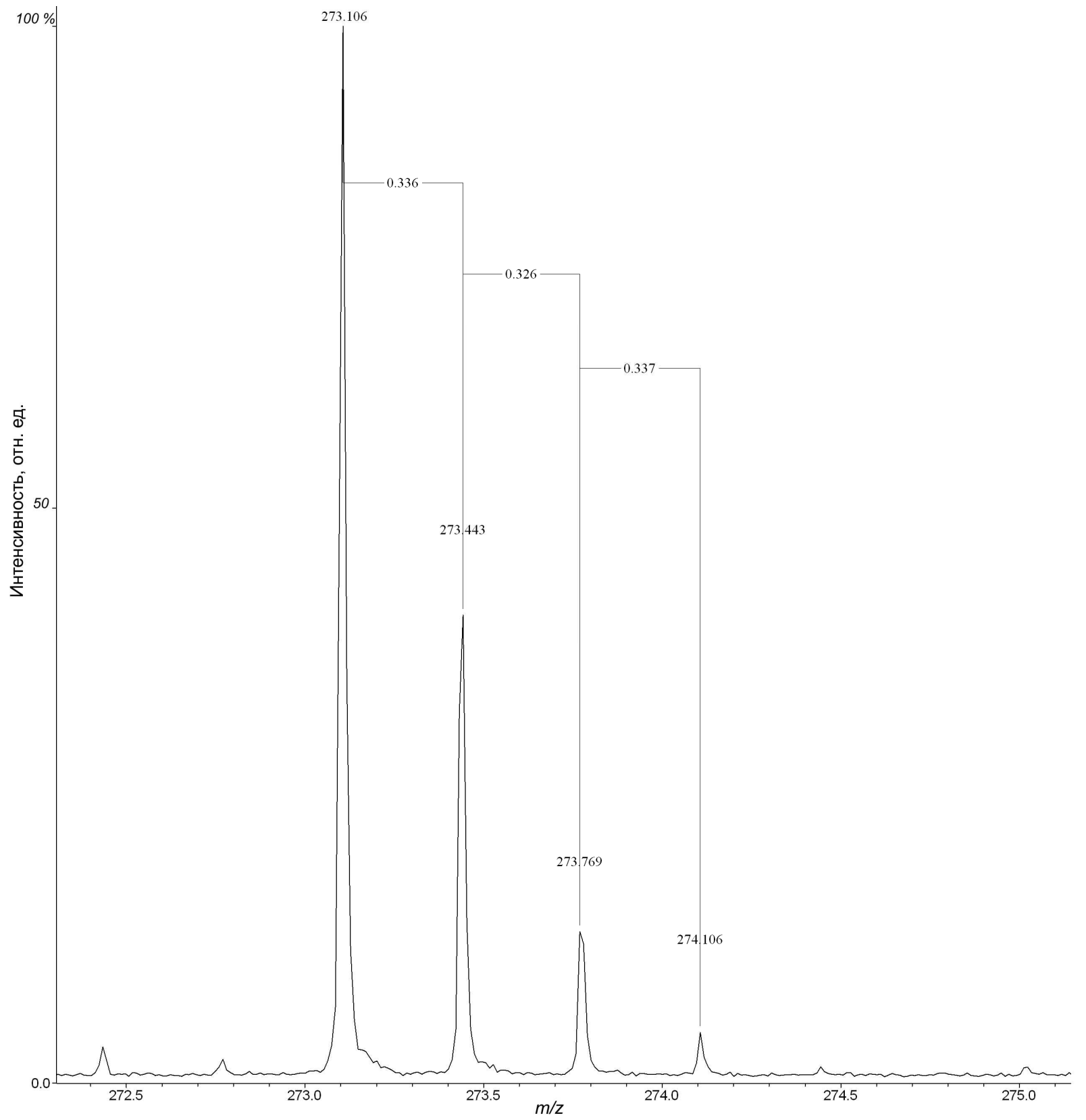

Рис. 2. Фрагменты масс-спектра анионов глицирризиновой кислоты 1: трианиона $[\mathrm{M}-3 \mathrm{H}]^{-3} \mathrm{c} m / z, 273,106$ и изотопного трианиона $[\mathrm{M}-3 \mathrm{H}+1]^{-3} \mathrm{c} m / z, 273,443$ 


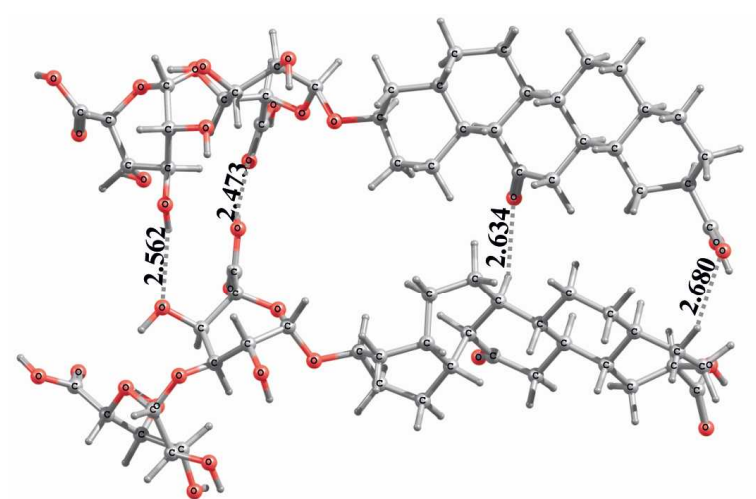

2, $\Delta \mathrm{E}($ компл $)=9.5$ ккал/моль

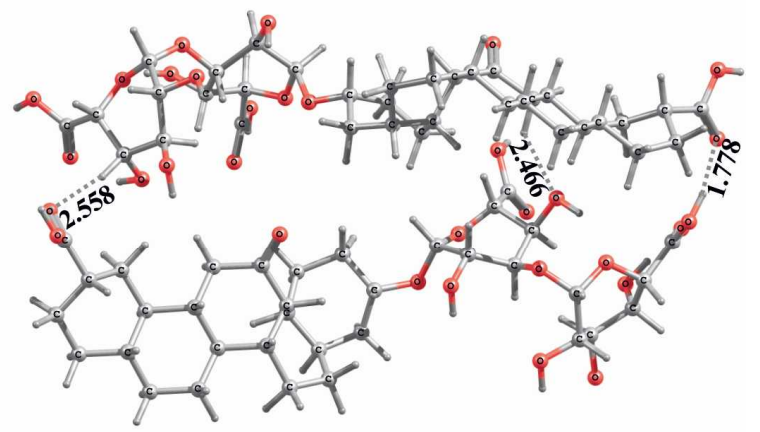

3, $\Delta E($ компл) $=15.1$ ккал/моль

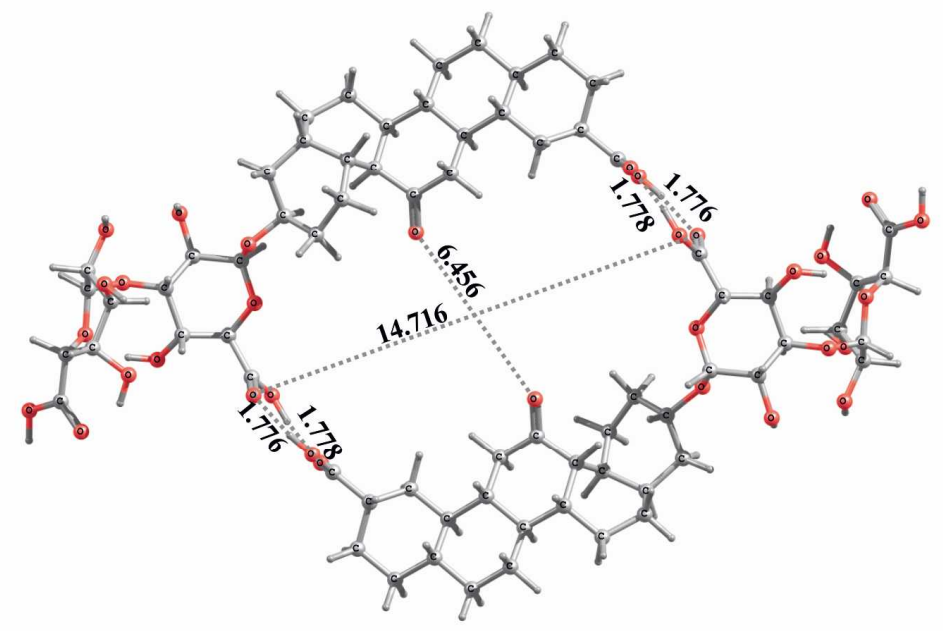

4,

$\Delta \mathrm{E}($ компл $)=16.2$ ккал/моль

Рис. 3. Геометрическое строение бимолекулярных комплексов глицирризиновой кислоты (структуры 2-4) по данным полуэмпирических РМ3 расчетов (расстояния в ангстремах)

\section{Заключение}

Масс-спектрометрия с ионизацией электрораспылением использована для изучения процессов формирования автоассоциатов глицирризиновой кислоты (ГК). Данные масс-спектрометрии доказывают наличие димеров и тримеров ГК для образцов $0,2 \%$-ного раствора моноаммониевой соли глицирризиновой кислоты при рН 5,5 и 2.

Данные, полученные методом масс-спектрометрии с ионизацией электрораспылением, согласуются с проведенными квантово-химическими расчетами самоассоциатов глицирризиновой кислоты. Квантовохимическими расчетами показано, что для глицирризиновой кислоты возможно образование кластеров общего вида Xn со значением n от 1 до $\mathrm{n}=6$. В ассоциате ГК, состоящем из двух молекул, присутствует полость, достаточная для включения соразмерных молекул-гостей.

Данные масс-спектрометрии и результаты квантово-химических расчетов демонстрируют, что наибольшей стабильностью обладают кластеры, построенные по принципу «голова-хвост».

\section{Список литературы}

1. Sarnthein-Graf C., La Mesa C. Association of saponins in water and water-gelatine mixtures // Thermochimica Acta. 2004. Vol. 418, N1-2. Pp. 79-84.

2. Sidhu G.S., Oakenfull D.G. A mechanism for the hypocholesterolaemic activity of saponins // British Journal of Nutrition. 1986. Vol. 55, N3. Pp. 643-649. 
3. Толстиков Г.А., Балтина Л.А., Шульц Э.Э. Покровский А.Г. Глицирризиновая кислота // Биоорганическая химия. 1997. Т. 23, №9. С. 691-703.

4. Толстикова Т.Г., Толстиков А.Г., Толстиков Г.А. На пути к низкодозным лекарствам // Вестник Российской академии наук. 2007. Т. 77, №10. С. 867-874.

5. Стоник В.А., Толстиков Г.А. Природные соединения и создание отечественных лекарственных препаратов // Вестник Российской академии наук. 2008. Т. 78, №8. С. 675-682.

6. Толстикова Т.Г., Сорокина И.В., Брызгалов А.О., Лифшиц Г.И., Хвостов М.В. Использование подхода комплексообразования с глицирризиновой кислотой для создания новых кардиотропных средств // Биомедицина. 2006. №4. C. 115-117.

7. Vögtle F., Weber E. Multidentate acyclic neutral ligands and their complexation // Angewandte Chemie Int. Ed. 1979. Vol. 18, N10. P. 753-776.

8. Weber E., Vögtle F. Classification and nomenclature of coronands, cryptands, podands, and of their complexes // Inorg. Chim. Acta. 1980. Vol. 45, N2. P. 65-67.

9. Frisch M.J., Trucks G.W., Schlegel H.B., Scuseria G.E., Robb M.A., Cheeseman J.R., Zakrzewski V.G., Montgomery J.A. Jr., Stratmann R.E., Burant J.C., Dapprich S., Millam J.M., Daniels A.D., Kudin K.N., Strain M.C., Farkas O., Tomasi J., Barone V., Cossi M., Cammi R., Mennucci B., Pomelli C., Adamo C., Clifford S., Ochterski J., Petersson G.A., Ayala P.Y., Cui Q., Morokuma K., Salvador P., Dannenberg J.J., Malick D.K., Rabuck A.D., Raghavachari K., Foresman J.B., Cioslowski J., Ortiz J.V., Baboul A.G., Stefanov B.B., Liu G., Liashenko A., Piskorz P., Komaromi I., Gomperts R., Martin R.L., Fox D.J., Keith T., Al-Laham M.A., Peng C.Y., Nanayakkara A., Challacombe M., Gill P.M.W., Johnson B., Chen W., Wong M.W., Andres J.L., Gonzalez C., Head-Gordon M., Replogle E.S., Pople J.A. Gaussian 98. Revision A.9. Gaussian, Inc., Pittsburgh PA. 1998.

10. Стариков А.Г., Миняев Р.М., Старикова А.А., Минкин В.И. Механизм аддуктообразования пиридина с $\beta$-дикетонатами Zn(II) и Сu(II) // Вестник ЮНЦ РАН. 2011. Т. 7, №2. С. 27-34.

11. Chemcraft. URL: www.chemcraftprog.com. Version 1.6 (build 304).

Поступило в редакичию 21 мая 2012 2.

После переработки 23 октября 2012 г. 
Borisenko S.N. ${ }^{l}$, Lekar A.V. ${ }^{2}$, Milov A.A. ${ }^{3}$, Vetrova E.V. ${ }^{l}$, Borisenko N.I. ${ }^{2 *}$ MASS-SPECTROMETRY AND QUANTUM-CHEMICAL STUDY ЩA SELF-ASSOCIATION PROCESSES OF GLYCYRRHIZINIC ACID MOLECULES

${ }^{I}$ Institute of Physical and Organic Chemistry, Southern Federal University, Stachka Ave, 194/2, Rostov-on-Don, 344090 (Russia)

${ }^{2}$ Ecological and Analytical Center, Southern Federal University,Zorge Str., 7, Rostov-on-Don, 344090 (Russia), e-mail: boni@ipoc.rsu.ru

${ }^{3}$ Southern Scientific Center of Russian Academy of Sciences, st. Chehova, 41, Rostov-on-Don, 344006 (Russia)

The mass spectrometry with electrospray ionization has used to study the processes of the formation the selfassociation complexes Glycyrrhizinic acid (GA). The data of mass spectrometry have proved the presence of dimers and trimers of GA for samples of 0,2\% Monoammonium salt of GA at $\mathrm{pH} 5,5$ and $\mathrm{pH}$ 2. These data are consistent with the quantum-chemical calculations of self-associates of glycyrrhizic acid. The quantum-chemical calculations predict the formation of clusters of the general form Xn with a value of $n$ from 1 to $n=6$. The data of mass spectrometry and the results of quantum chemical calculations demonstrated that the most stable clusters have built on the principle of «head - tail». Self-associated complex of GA composed of two molecules of GA create a cavity between them, with the size which is enough to include guest molecules with the similar size.

Keywords: self-association, glycyrrhizinic acid, mass-spectrometry, electrospray ionization, quantum-chemical research, complexation, supramolecular complex.

\section{References}

1. Sarnthein-Graf C., La Mesa C. Thermochimica Acta, 2004, vol. 418, no. 1-2, pp. 79-84.

2. Sidhu G.S., Oakenfull D.G. British Journal of Nutrition, 1986, vol. 55, no. 3, pp. 643-649.

3. Tolstikov G.A., Baltina L.A., Shul'ts E.E. Pokrovskii A.G. Bioorganicheskaia khimiia, 1997, vol. 23, no. 9, pp. 691-703. (in Russ.).

4. Tolstikova T.G., Tolstikov A.G., Tolstikov G.A. Vestnik Rossiiskoi akademii nauk, 2007, vol. 77, no. 10, pp. 867-874. (in Russ.).

5. Stonik V.A., Tolstikov G.A. Vestnik Rossiiskoi akademii nauk, 2008, vol. 78, no. 8, pp. 675-682. (in Russ.).

6. Tolstikova T.G., Sorokina I.V., Bryzgalov A.O., Lifshits G.I., Khvostov M.V. Biomeditsina, 2006, no. 4, pp. $115-117$. (in Russ.).

7. Vögtle F., Weber E. Angewandte Chemie Int. Ed., 1979, vol. 18, no. 10. pp. 753-776.

8. Weber E., Vögtle F. Inorg. Chim. Acta., 1980, vol. 45, no. 2, pp. 65-67.

9. Frisch M.J., Trucks G.W., Schlegel H.B., Scuseria G.E., Robb M.A., Cheeseman J.R., Zakrzewski V.G., Montgomery J.A. Jr., Stratmann R.E., Burant J.C., Dapprich S., Millam J.M., Daniels A.D., Kudin K.N., Strain M.C., Farkas O., Tomasi J., Barone V., Cossi M., Cammi R., Mennucci B., Pomelli C., Adamo C., Clifford S., Ochterski J., Petersson G.A., Ayala P.Y., Cui Q., Morokuma K., Salvador P., Dannenberg J.J., Malick D.K., Rabuck A.D., Raghavachari K., Foresman J.B., Cioslowski J., Ortiz J.V., Baboul A.G., Stefanov B.B., Liu G., Liashenko A., Piskorz P., Komaromi I., Gomperts R., Martin R.L., Fox D.J., Keith T., Al-Laham M.A., Peng C.Y., Nanayakkara A., Challacombe M., P.M.W. Gill, Johnson B., Chen W., Wong M.W., Andres J.L., Gonzalez C., Head-Gordon M., Replogle E.S., Pople J.A. Gaussian 98. Revision A.9. Gaussian, Inc., Pittsburgh PA. 1998.

10. Starikov A.G., Miniaev R.M., Starikova A.A., Minkin V.I. Vestnik Iuzhnogo nauchnogo tsentra RAN, 2011, vol. 7, no. 2, pp. 27-34. (in Russ.).

11. Chemcraft. URL: www.chemcraftprog.com. Version 1.6 (build 304).

Received May 21, 2012

Revised October 23, 2012

\footnotetext{
* Corresponding author.
} 